\title{
Effects of Graphene/Silver Nanocomposite on the Microstructure of Amorphous Mg-based Hydride
}

\author{
Huang Lin-jun ${ }^{*}$, Wang Yan-xin ${ }^{*}$, Tang Jian-guo ${ }^{*}$,Wang Yao, Liu Ji-xian, Jiao Ji-qing, Wang Wei \\ College of Materials Science and Engineering, Qingdao University, Qingdao 266071, China \\ *E-mail: newboy66@126.com, yanxin_2008@126.com, tang@qdu.edu.cn
}

doi: $10.20964 / 2016.12 .10$

Received: 7 July 2016 / Accepted: 22 September 2016 / Published: 10 November 2016

The influence of a graphene/silver (G/A) nanocomposite coating layer on the microstructural evolution and surface oxidation of a $\mathrm{Mg}-\mathrm{Ni}-\mathrm{La}$ hydride is investigated systematically by XRD, SEM, EDS and HRTEM in detail. SEM and EDS reveal that the existence of the G/A composite prevents the electrode from pulverizing and oxidizing. The oxygen content in the surface of the electrode is reduced from $21.26 \%$ to $9.83 \%$ after 50 cycles for a Mg-Ni-La electrode with 0.2 mass fraction of G/A. HRTEM shows that the amorphous electrodes with no G/A coating are almost all crystallized, and that the stable $\mathrm{Mg}_{2} \mathrm{NiH}_{4}, \alpha-\mathrm{Mg}, \mathrm{MgH}_{2}$ and $\mathrm{LaH}_{2}$ phases are present with grain sizes as large as $100-120 \mathrm{~nm}$ after 50 cycles of charging/discharging. The G/A coating reduces the corrosion and oxidation of the electrode alloy and provides both a pathway for hydrogen diffusion and active sites for the redox reaction of hydrogen. All these factors generate a significant enhancement of the discharge capacity by about $250 \mathrm{mAhg}^{-1}$ in each cycle (after activation) for $\mathrm{Mg}-\mathrm{Ni}-\mathrm{La}$ electrodes with $0.2 \mathrm{G} / \mathrm{A}$ nanocomposites.

Keywords: electrode alloy; graphene coating; electrochemical property; surface modification.

\section{$\underline{\text { FULL TEXT }}$}

(C) 2016 The Authors. Published by ESG (www.electrochemsci.org). This article is an open access article distributed under the terms and conditions of the Creative Commons Attribution license (http://creativecommons.org/licenses/by/4.0/). 